\title{
A phase II study of a personalized peptide vaccination for chemotherapy-resistant advanced pancreatic cancer patients
}

\author{
SHIGERU YUTANI $^{1}$, NOBUKAZU KOMATSU ${ }^{1}$, MUNEHIRO YOSHITOMI ${ }^{2}$, SATOKO MATSUEDA $^{1,3}$, \\ KOJI YONEMOTO ${ }^{4}$, TAKASHI MINE ${ }^{2}$, MASANORI NOGUCHI $^{3}$, YUKI ISHIHARA ${ }^{1}$, \\ AKIRA YAMADA $^{3}$, KYOGO ITOH ${ }^{1}$ and TETSURO SASADA ${ }^{1}$
}

Departments of ${ }^{1}$ Immunology and Immunotherapy, and ${ }^{2}$ Surgery, Kurume University School of Medicine, Kurume, Fukuoka 830-0011; ${ }^{3}$ Research Center for Innovative Cancer Therapy and

${ }^{4}$ Biostatistics Center, Kurume University, Kurume, Fukuoka 830-0011, Japan

Received March 22, 2013; Accepted May 9, 2013

DOI: 10.3892/or.2013.2556

\begin{abstract}
Pancreatic cancer is one of the most aggressive cancers with a median survival time (MST) of $<6$ months in chemotherapy-resistant patients. Therefore, the development of novel treatment modalities is needed. In the present study, a phase II study of personalized peptide vaccination (PPV) was conducted, in which vaccine antigens were selected and administered based on the pre-existing IgG responses to 31 different pooled peptides, for 41 chemotherapy-resistant advanced pancreatic cancer patients. No vaccine-related severe adverse events were observed. IgG responses specific to at least one of the vaccine peptides were augmented in 14 of 36 patients (39\%) and in 18 of 19 patients (95\%) tested after the 5th and 11 th vaccination, respectively. MST from the first vaccination was 7.9 months with a 1-year survival rate of $26.8 \%$. Higher serum amyloid A (SAA) and C-reactive protein (CRP) levels in pre-vaccination plasma were unfavorable factors for overall survival (OS). Due to the safety profile and the potential clinical efficacy, the conduction of additional clinical trials of PPV for chemotherapy-resistant advanced pancreatic cancer patients is warranted.
\end{abstract}

\section{Introduction}

Pancreatic cancer, the fourth leading cause of cancer-related mortality worldwide, constitutes one of the most aggressive types of cancer (1). There have been substantial advances in the therapeutic modalities for advanced pancreatic cancer, including carbon beam ion radiotherapy (2), systemic chemo-

Correspondence to: Dr Shigeru Yutani, Department of Immunology and Immunotherapy, Kurume University School of Medicine, 67 Asahi-machi, Kurume, Fukuoka 830-0011, Japan

E-mail: yutani@med.kurume-u.ac.jp

Key words: personalized peptide vaccine, chemotherapy-resistant pancreatic cancer, overall survival, $\operatorname{IgG}$ response therapies using gemcitabine (GEM), tegaful-gimeracil-oteracil potassium (S-1) (3) and oxaliplatin, irinotecan, fluorouracil, leucovorin (Folfirinox) (4), as well as an EGFR-inhibitor erlotinib (5). However, despite these advances, the median survival time (MST) of advanced pancreatic cancer patients from the first or second line of chemotherapy still remains approximately 7-11 (1-5) or 4-6 months $(2,6)$, respectively. Therefore, the development of novel therapeutic approaches including cancer vaccines is needed.

We previously devised a new regimen of peptide-based vaccination, named personalized peptide vaccination (PPV), in which vaccine antigens were selected from 31 different pooled peptides, and administered based on both HLA-class IA types and levels of peptide-specific IgG responses before vaccination (7-10). In our previous clinical trials, immune responses triggered by PPV were well-associated with overall survival (OS) in advanced pancreatic cancer patients under PPV in combination with GEM as the first-line therapy $(7,8)$. GEM did not inhibit immune responses induced by PPV. Furthermore, the MST of advanced pancreatic cancer patients with positive $(n=10)$ or negative $(n=8)$ immune responses was 15.5 and 6 months, respectively, when non-resectable pancreatic cancer patients were treated with PPV and GEM as the first-line therapy. However, there is no trial of PPV for chemotherapy-resistant advanced pancreatic cancer currently available. Consequently, in the present study, a phase II study of PPV in chemotherapy-resistant advanced pancreatic cancer patients was performed.

\section{Materials and methods}

Patients. Patients pathologically and/or clinically diagnosed with pancreatic cancer were eligible for inclusion in the present study, when they had failed at least first-line chemotherapy and showed positive $\operatorname{IgG}$ responses to at least 2 of the 31 different vaccine candidate peptides as previously reported (10). Additional inclusion criteria were the following: age between 20 and 80 years, Eastern Cooperative Oncology Group (ECOG) performance status of 0 or 1 , positive status for the HLA-A2, -A24, -A3 supertype (A3, A11, A31 or A33) or -A26, life expectancy of at least 12 weeks, and adequate 
hematologic, hepatic and renal function. Exclusion criteria included pulmonary, cardiac or other systemic diseases, acute infection, a history of severe allergic reactions, pregnancy or nursing, and other inappropriate conditions for enrollment as judged by clinicians. The protocol was approved by the Kurume University Ethics Committee, and was registered in the UMIN Clinical Trials Registry (UMIN \#08167). After a full explanation of the protocol, a written informed consent was obtained from all the patients prior to enrollment.

Clinical protocol. This was an open-label phase II study, in which the main objectives were to evaluate safety and to address whether PPV in combination with additional chemotherapeutic regimens for chemotherapy-resistant pancreatic cancer patients prolongs MST. Thirty-one peptides, the safety and immunological effects of which were reported in previous clinical studies (8-11), were employed for vaccination [12 peptides for HLA-A2, 14 for HLA-A24, 9 for HLA-A3 supertype (A3, A11, A31 or A33) and 4 for HLA-A26]. The peptides were prepared under the conditions of Good Manufacturing Practice (GMP) by PolyPeptide Laboratories (San Diego, CA, USA) and the American Peptide Company (Vista, CA, USA).

The peptides for vaccination to individual patients were selected in consideration of the pre-existing host immunity before vaccination, by assessing the titers of $\operatorname{IgG}$ specific to each of the 31 different vaccine candidates (10). A maximum of 4 peptides ( $3 \mathrm{mg} / \mathrm{each}$ peptide), which were selected based on the results of HLA typing and peptide-specific IgG titers, in complex with incomplete Freund's adjuvant (Montanide ISA 51; Seppic, Paris, France) were subcutaneously administered once a week for 6 consecutive weeks.

After the first cycle of 6 vaccinations, up to 4 vaccine peptides were re-selected according to the titers of peptide-specific IgG and administered every 2 weeks. Vaccine peptides were re-selected at every cycle of 6 vaccinations until the discontinuation of PPV. Adverse events were monitored according to the National Cancer Institute Common Terminology Criteria for Adverse Events (NCI-CTCAE) version 3.0. Complete blood counts and serum biochemical tests were performed at every cycle of 6 vaccinations. The clinical responses were evaluated by the Response Evaluation Criteria in Solid Tumors (RECIST) with radiological findings of computed tomography (CT) scanning or magnetic resonance imaging (MRI) before and after vaccinations.

Measurement of laboratory markers. Levels of C-reactive protein (CRP), serum amyloid A (SAA) and IL-6 in plasma were examined by ELISA using kits from R\&D Systems (Minneapolis, MN, USA), Invitrogen (Carlsbad, CA, USA) and eBioscience (San Diego, CA, USA), respectively. Bead-based multiplex assays were used to measure cytokines, including IL-4, IL-13, IL-21, IP-10, BAFF and TGF- $\beta$ with the Luminex 200 system (Luminex, Austin, TX, USA).

Measurement of immunoglobulins (Igs) reactive to each of the 31 different peptides. The levels of Igs reactive to each of the 31 different peptides were measured using the Luminex 200 system as previously reported (9-11). In brief, plasma was incubated with $100 \mu \mathrm{l}$ of peptide-coupled color-coded beads for $1.5 \mathrm{~h}$ at $30^{\circ} \mathrm{C}$, followed by washing and incubation with $100 \mu \mathrm{l}$ of biotinylated goat anti-human IgG (Vector Laboratories, Burligame, CA, USA). After washing, $100 \mu \mathrm{l}$ of streptavidin-PE (Invitrogen) was added and incubated for $30 \mathrm{~min}$ at $30^{\circ} \mathrm{C}$. After washing, the fluorescence on the beads was detected using the Luminex 200 system. The Igs levels were expressed in fluorescence intensity units (FIU) as previously reported (9-11). Peptide-specificity of IgG against each of the 31 peptides was confirmed (unpublished data).

Statistical methods. The Wilcoxon signed-rank test and paired t-test were used to compare differences between pre- and post-vaccination measurements. OS was calculated from the first day of peptide vaccination until the day of death or the last day when the patient was known to be alive. Prognostic factors for OS were evaluated by univariate and multivariate analyses with the Cox proportional hazards regression model. Curves for OS were estimated using the Kaplan-Meier method, and the log-rank test was conducted for the comparison of survival curves. Two-sided P-values of $<0.05$ were considered to indicate statistically significant differences. All statistical analyses were conducted using the JMP version 10.0.1 software (SAS Institute Inc., Cary, NC, USA).

\section{Results}

Patient characteristics. Between November 2008 and March 2011, 41 advanced pancreatic cancer patients who had failed at least first-line chemotherapy were included in the present study. Patient characteristics are listed in Table I. There were 27 male and 14 female subjects with a median age of 61 years (range, 44-78). All patients had advanced stages of cancer (stage IVa, $n=7$; IVb, $n=24$; recurrent, $n=10$ ). Prior to enrollment, the patients had failed $1(n=11), 2(n=24), 3(n=5)$ or $4(n=1)$ regimen(s) of chemotherapy. The median duration of chemotherapy prior to PPV was 8 months with a range from 1 to 36 months. The performance status at the time of enrollment was grade $0(n=37)$ or $1(n=4)$. The numbers of vaccine peptides employed at the first cycle of vaccinations were 4 peptides in 33 patients, 3 in 5 patients and 2 in 3 patients. The median number of vaccinations was 10 with a range of 3 to 36 . PPV was combined with GEM $(n=11), S-1(n=6)$, GEM and S-1 $(n=8)$ or other combinations of chemotherapeutic agents including CDDP-based regimens $(n=8)$. PPV alone was administered to 8 patients, since chemotherapy could not be tolerated $(n=4)$ or due to patient refusal $(n=4)$.

Toxicities. A grade 1 or 2 dermatological reaction at the injection site was observed in 39 cases. Anemia $(n=15)$, lymphocytopenia $(n=20)$, thrombocytopenia $(n=11)$, leukocytopenia $(n=7)$, hypoalbuminemia $(n=15)$ and hyperglycemia $(n=8)$ were also frequently observed. Grade 3 adverse events included anemia $(n=1)$, lymphocytopenia $(n=1)$, hypertension $(n=1)$, GGT increase $(n=1)$ and creatinine increase $(n=1)$. According to assessment by the Independent Safety Evaluation Committee in this trial, all the grade 3 adverse events were concluded to be not directly associated with PPV.

Humoral responses to peptides. IgG responses specific to the vaccine peptides in pre- and post-vaccination plasma samples 
Table I. Patient characteristics.

\begin{tabular}{lc}
\hline Characteristic & Value \\
\hline Age (years), median (range) & 61 (44-78) \\
Gender, $\mathrm{n}$ & \\
Male & 27 \\
Female & 14
\end{tabular}

Disease location, $\mathrm{n}$

$\begin{array}{lr}\text { Head } & 14 \\ \text { Body } & 15 \\ \text { Limbs } & 6 \\ \text { Body and limbs } & 6\end{array}$

Performance status, $\mathrm{n}$

$$
0
$$$$
1
$$

Stage, $\mathrm{n}$

IVa

$\mathrm{IVb}$

Recurrent

7
24
10

No. of previous regimens, $n$

$$
1
$$

2

3

4

14

5

6

6

Duration of previous treatment (months), median (range)

No. of vaccinations, median (range)

Combined treatment, $\mathrm{n}$

$(-)$

\section{GEM}

S-1

GEM and S-1

Other regimens

Treatment response, $\mathrm{n}$

$\begin{array}{ll}\text { SD } & 28 \\ \text { PD } & 13\end{array}$

Overall survival time (days), median $(95 \% \mathrm{CI})$

$238(151-313)$

GEM, gemcitabine; S-1, tegaful-gimeracil-oteracil potassium; SD, stable disease; PD, progressive disease; CI, confidence interval.

were analyzed. Post-vaccination plasma samples were available from 36 and 17 patients after the 5th and 11th vaccination, respectively. When peptide-specific IgG titers to at least one of the vaccine peptides in the post-vaccination plasma were $>2$-fold higher compared to those in the pre-vaccination plasma, antigen-specific humoral responses were considered to be increased. The $\mathrm{IgG}$ responses specific to at least one of the vaccine peptides were augmented in 14 of 36 patients $(39 \%)$ and in 18 of 19 patients (95\%) after the 5th and 11th vaccination, respectively (Table II).

\begin{tabular}{|c|c|c|c|c|}
\hline \multirow[b]{2}{*}{ Patient no. } & \multirow[b]{2}{*}{ Peptide } & \multicolumn{3}{|c|}{ IgG response } \\
\hline & & Pre & 5 th & 11 th \\
\hline \multirow[t]{4}{*}{1} & ppMAPkkk-432 & 43 & 40 & na \\
\hline & WHSC2-103 & 68 & 69 & na \\
\hline & HNRPL-501 & 191 & 638 & na \\
\hline & HNRPL-140 & 209 & 189 & na \\
\hline \multirow[t]{4}{*}{2} & SART3-109 & 226 & 1,896 & na \\
\hline & Lck-422 & 44 & 66 & na \\
\hline & СурВ-129 & 23 & 45 & na \\
\hline & WHSC2-103 & 322 & 401 & na \\
\hline \multirow[t]{4}{*}{3} & PSA-248 & 28 & 4,999 & 28,025 \\
\hline & MRP3-1293 & 75 & 70 & 3,259 \\
\hline & SART2-161 & 37 & 38 & $\mathbf{7 , 8 6 0}$ \\
\hline & Lck-486 & 38 & 31 & 23,697 \\
\hline \multirow[t]{4}{*}{4} & MRP3-503 & 57 & 56 & na \\
\hline & MRP3-1293 & 79 & 69 & na \\
\hline & SART2-161 & 51 & 53 & na \\
\hline & Lck-486 & 53 & ND & na \\
\hline \multirow[t]{5}{*}{5} & СурB-129 & 161 & 120 & 12,717 \\
\hline & ppMAPkkk-432 & 368 & ND & ND \\
\hline & UBE2V-43 & 396 & 399 & 60,508 \\
\hline & SART3-302 & 272 & 235 & 11,267 \\
\hline & $\underline{\text { HNRPL-501 }}$ & 150 & 343 & ND \\
\hline \multirow[t]{2}{*}{6} & HNRPL-140 & 13 & ND & na \\
\hline & SART3-302 & 40 & ND & na \\
\hline \multirow[t]{4}{*}{7} & SART3-109 & 42 & 52 & na \\
\hline & SART3-511 & 27 & ND & na \\
\hline & Lck-90 & 13 & ND & na \\
\hline & Lck-449 & 45 & ND & na \\
\hline \multirow[t]{5}{*}{8} & SART2-93 & 32 & 18 & na \\
\hline & PAP-213 & 1,249 & 1,573 & na \\
\hline & EGF-R-800 & 40 & ND & na \\
\hline & MRP3-503 & 98 & 38 & na \\
\hline & $\underline{\text { SART3-109 }}$ & 23 & 11 & na \\
\hline \multirow[t]{5}{*}{9} & Lck-246 & 376 & 623 & 3,264 \\
\hline & UBE2V-43 & 188 & ND & 16,549 \\
\hline & UBE2V-85 & 294 & 314 & 2,053 \\
\hline & SART3-302 & 207 & 330 & 1,929 \\
\hline & $\underline{\text { HNRPL-140 }}$ & ND & 494 & 2,780 \\
\hline \multirow[t]{4}{*}{10} & HNRPL-501 & 578 & ND & ND \\
\hline & UBE2V-85 & 70 & ND & 14 \\
\hline & SART3-302 & 36 & ND & ND \\
\hline & SART3-309 & 18 & ND & ND \\
\hline \multirow[t]{3}{*}{11} & SART3-109 & 21 & ND & 653 \\
\hline & MRP3-503 & 69 & ND & 14,787 \\
\hline & PTHrP-102 & 14 & ND & ND \\
\hline \multirow[t]{4}{*}{12} & SART2-93 & 164 & ND & na \\
\hline & Lck-208 & 206 & 13 & na \\
\hline & Lck-486 & 245 & 298 & na \\
\hline & EZH2-735388 & 503 & na & \\
\hline
\end{tabular}

Table II. IgG responses to the vaccinated peptides. 
Table II. Continued.

\begin{tabular}{|c|c|c|c|c|c|c|c|c|c|}
\hline \multirow[b]{2}{*}{ Patient no. } & \multirow[b]{2}{*}{ Peptide } & \multicolumn{3}{|c|}{$\mathrm{IgG}$ response } & \multirow[b]{2}{*}{ Patient no. } & \multirow[b]{2}{*}{ Peptide } & \multicolumn{3}{|c|}{ IgG response } \\
\hline & & Pre & 5 th & 11th & & & Pre & 5 th & 11th \\
\hline \multirow[t]{2}{*}{12} & $\underline{\text { Lck-422 }}$ & 783 & 532 & na & \multirow[t]{6}{*}{23} & PAP-213 & 13 & 123 & 4,179 \\
\hline & $\underline{\text { HNRPL-140 }}$ & 456 & 380 & na & & Lck-486 & 25 & 580 & 2,552 \\
\hline \multirow[t]{2}{*}{13} & SART3-109 & 1,475 & 1,279 & na & & Lck-449 & 37 & 37 & 43 \\
\hline & Lck-486 & 1,644 & 1,833 & na & & WHSC2-103 & 40 & 14 & 165 \\
\hline \multirow{4}{*}{14} & SART3-109 & 2,309 & 2,136 & 6,782 & & $\underline{\text { SART3-511 }}$ & ND & 289 & 173 \\
\hline & MRP3-1293 & 43 & 40 & 23,180 & & $\underline{\text { PAP-248 }}$ & ND & 1,200 & 63 \\
\hline & SART2-161 & 32 & 27 & ND & \multirow[t]{4}{*}{24} & PAP-213 & 122 & 122 & na \\
\hline & Lck-486 & 1,515 & 1,234 & 267,768 & & Lck-449 & 129 & 102 & na \\
\hline \multirow[t]{5}{*}{15} & SART3-109 & 1,500 & 5,872 & 180,917 & & СурB-129 & 186 & 183 & na \\
\hline & SART2-161 & 31 & 22 & 3,278 & & WHSC2-103 & 69 & ND & na \\
\hline & Lck-486 & 650 & 224 & 58,780 & \multirow[t]{3}{*}{25} & PAP-213 & 16 & 2,772 & na \\
\hline & Lck-488 & 54 & 37 & 21,889 & & PSA-248 & 64 & 1,372 & na \\
\hline & $\underline{\text { SART3-511 }}$ & 99 & 57 & ND & & Lck-486 & 17 & 105 & na \\
\hline \multirow[t]{6}{*}{16} & SART3-511 & 1,699 & 1,503 & 1,522 & \multirow[t]{4}{*}{26} & СурB-129 & 90 & 81 & 105 \\
\hline & PAP-248 & 70 & 69 & ND & & Lck-246 & 20 & 12 & 39 \\
\hline & Lck-422 & 180 & ND & 16 & & SART3-309 & 12 & 374 & 4,738 \\
\hline & WHSC2-103 & 188 & ND & 2,629 & & PAP-248 & 21 & ND & ND \\
\hline & $\underline{\text { Lck-90 }}$ & 35 & 45 & 63 & \multirow[t]{5}{*}{27} & SART2-93 & 11 & ND & 55 \\
\hline & СурB-129 & 16 & 23 & 20 & & SART3-109 & 156 & 222 & 1,871 \\
\hline \multirow[t]{5}{*}{17} & ppMAPkkk-432 & 83 & 88 & ND & & Lck-486 & 185 & 313 & 12,511 \\
\hline & SART3-109 & 62 & 49 & ND & & Lck-488 & 15 & 12 & 3,980 \\
\hline & Lck-486 & 2,176 & 2,191 & $3,523,034$ & & $\underline{\text { PAP-213 }}$ & ND & 14 & ND \\
\hline & PTHrP-102 & 129 & 162 & 135 & \multirow[t]{4}{*}{28} & PAP-213 & 31 & 44 & 657 \\
\hline & $\underline{\text { SART2-93 }}$ & 47 & 100 & 59 & & PSA-248 & 45 & 446 & 15,954 \\
\hline \multirow[t]{6}{*}{18} & MRP3-1293 & 103 & ND & na & & EGF-R-800 & 30 & 33 & 2,926 \\
\hline & Lck-486 & 5,731 & 10,510 & na & & Lck-486 & 22 & 23 & 11,356 \\
\hline & PSMA-624 & 99 & ND & na & 29 & SART2-93 & 11 & 11 & na \\
\hline & ppMAPkkk-432 & 126 & 115 & na & & Lck-486 & 25 & ND & na \\
\hline & $\underline{\text { SART3-109 }}$ & 55 & 50 & na & & Lck-488 & 14 & 16 & na \\
\hline & $\underline{\text { Lck-488 }}$ & 38 & 35 & na & 30 & СурB-129 & 246 & 232 & na \\
\hline 19 & СурВ-129 & 57 & 53 & na & & WHSC2-141 & 317 & 21 & na \\
\hline & ppMAPkkk-432 & 106 & 90 & na & & SART3-302 & 86 & 865 & na \\
\hline & HNRPL-501 & 974 & 934 & na & & Lck-208 & 11 & 2,016 & na \\
\hline & SART3-302 & 473 & 2,233 & na & 31 & SART2-93 & 40 & 37 & 478 \\
\hline & $\underline{\text { Lck-246 }}$ & 17 & 61 & na & & Lck-486 & 23 & 32 & 2,567 \\
\hline 20 & Lck-246 & 409 & 441 & 2,349 & & Lck-488 & 31 & 47 & 20,641 \\
\hline & EGF-R-800 & 83 & 134 & 183 & & PTHrP-102 & 40 & 46 & 523 \\
\hline & Lck-486 & 95 & 72 & $\mathbf{3 7 , 3 5 3}$ & 32 & WHSC2-141 & 433 & 398 & 20,518 \\
\hline & EZH2-735 & 117 & ND & 10,454 & & PSA-248 & 29 & 2,109 & 13,221 \\
\hline & СурB-129 & 183 & 192 & 190 & & MRP3-1293 & 149 & 4,155 & 11,903 \\
\hline & ppMAPkkk-432 & 120 & 185 & 233 & & & 121 & & \\
\hline 21 & PAP-213 & 48 & 98 & na & & Lck-486 & 121 & 18,577 & \\
\hline & Lck-486 & 20 & 22 & na & 33 & SART2-93 & 22 & 51 & 60 \\
\hline 22 & СурB-129 & 109 & 112 & 393 & & SART3-109 & 14 & ND & 16 \\
\hline & Lck-246 & 22 & 13 & 56 & & Lck-486 & 39 & ND & 2,479 \\
\hline & WHSC2-141 & 22 & ND & 15 & & $\underline{\text { SART2-161 }}$ & ND & 76 & 59 \\
\hline & SART3-302 & 631 & 1,459 & 5,168 & 34 & СурВ-129 & 263 & 239 & na \\
\hline & $\underline{\text { Lck-422 }}$ & 14 & 12 & 78 & & WHSC2-103 & 43 & ND & na \\
\hline
\end{tabular}
Table II. Continued. 
Table II. Continued.

\begin{tabular}{llrrr}
\hline & & \multicolumn{3}{c}{ IgG response } \\
\cline { 3 - 5 } Patient no. & \multicolumn{1}{c}{ Peptide } & Pre & \multicolumn{1}{c}{ 5th } & \multicolumn{1}{c}{ 11th } \\
\hline 34 & WHSC2-141 & 231 & 125 & na \\
& SART3-734 & 32 & ND & na \\
35 & MRP3-1293 & 62 & ND & na \\
& Lck-486 & 85 & ND & na \\
& SART3-734 & 123 & ND & na \\
& CypB-129 & 149 & 93 & na \\
36 & SART2-93 & 13 & 11 & 12 \\
& SART3-109 & 11,200 & 10,657 & 10,093 \\
& Lck-488 & 16 & 13 & $\mathbf{2 , 0 1 7}$ \\
& EGF-R-800 & ND & $\mathbf{1 1}$ & ND \\
\hline
\end{tabular}

Underlined peptides indicate the selection of new peptides for the second cycle of PPV. Bold values represent increased IgG responses. na, not applicable; ND, no data.

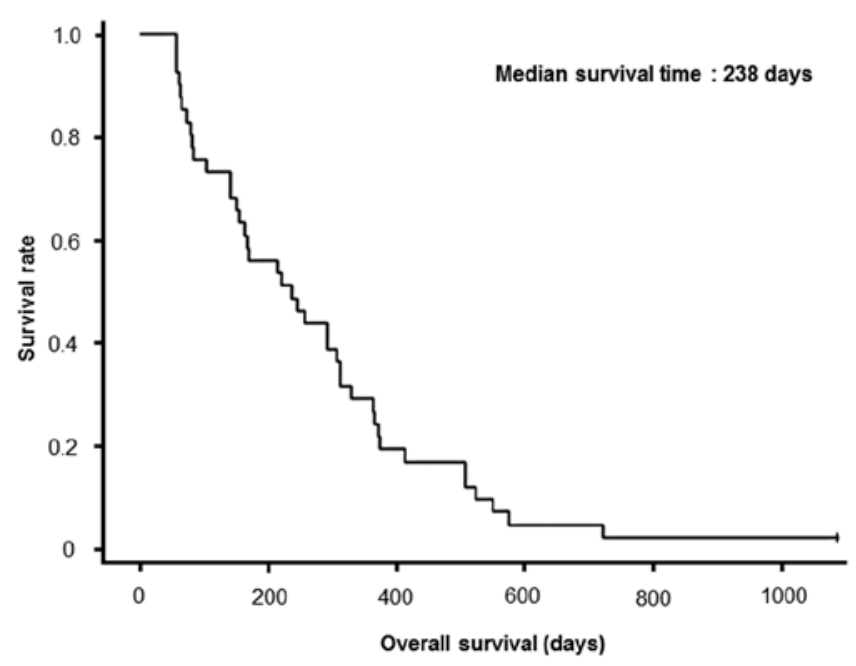

Figure 1. Kaplan-Meier survival analysis of the enrolled patients. The median survival time (MST) of patients who were vaccinated $(\mathrm{n}=41)$ was 238 days (7.9 months) and the 1-year survival rate was $26.8 \%$.

Laboratory markers. Two inflammation markers, CRP and SAA, and 7 cytokines including IL-4, IL-6, IL-13, IL-21, IP-10, BAFF and TGF- $\beta$, were examined in plasma before and after the 5 th vaccination. Since 5 of 41 patients did not complete the first cycle of 6 vaccinations due to rapid disease progression, they were excluded from the marker analysis. However, no significant differences before and after vaccinations were observed in the markers tested (data not shown).

Clinical outcome. No complete response (CR) or partial response (PR) was observed during PPV. Optimum clinical responses after the 6th vaccination or at discontinuation of PPV were observed in 28 cases of stable disease (SD) and 13 cases of progressive disease (PD) (Table I). MST from the first vaccination was 7.9 months (238 days) with a 1-year
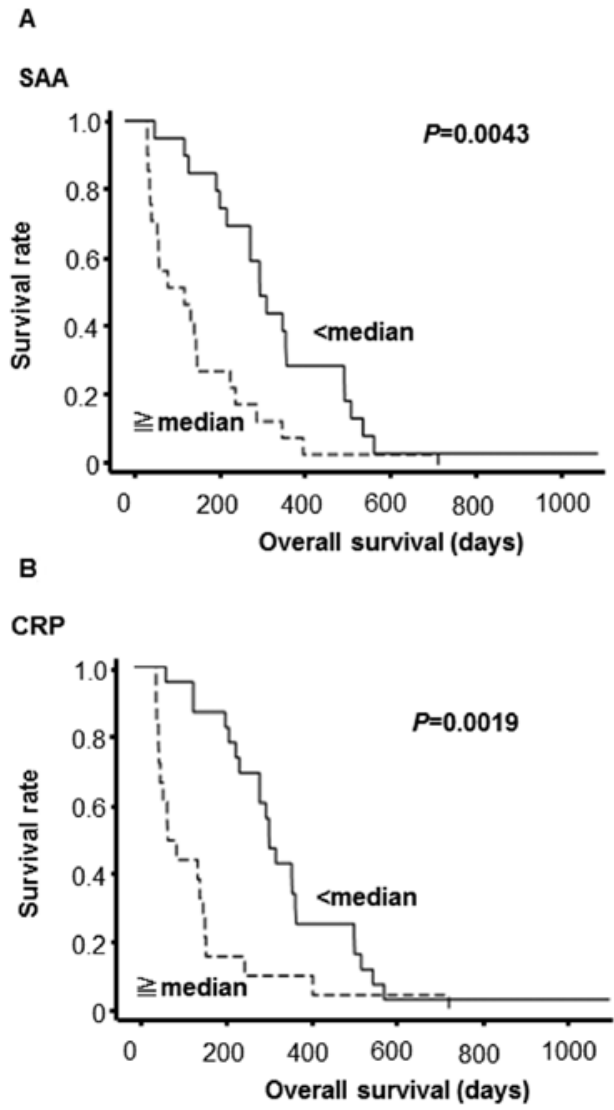

Figure 2. Evaluation of pre-vaccination factors by Kaplan-Meier survival analysis. Patients were divided into two subgroups according to the median value of the (A) SAA and (B) CRP levels before vaccination. Curves for overall survival were estimated by the Kaplan-Meier method, and differences in survival rates were evaluated using the log-rank test. SAA, serum-amyloid A; CRP, C-reactive protein.

survival rate of $26.8 \%$ (Table I). All the 41 patients, except for 1 patient, had succumbed to the disease at the time of examination. Survival curve is shown in Fig. 1. MST in patients treated with PPV in combination with $(n=33)$ or without $(n=8)$ chemotherapies was 9.6 or 3.1 months, respectively $(\mathrm{P}=0.0013)$ (data not shown). When calculated from the initiation of the first-line chemotherapy, MST of all 41 cases was 19.0 months [95\% confidence interval (CI), 15.0-25.0 months].

Prognostic factors for OS. Pre-vaccination prognostic biomarkers for OS were investigated in 36 patients who completed at least the first cycle of 6 vaccinations. SAA levels in pre-vaccination samples were found to be inversely associated with OS using the univariate Cox proportional hazards model [hazard ratio $(\mathrm{HR})$ per $1 \mathrm{mg} / \mathrm{dl}$ increment $=1.10$, 95\% CI=1.03-1.15, $\mathrm{P}=0.004]$ (Table III). CRP levels also showed a significant association $(\mathrm{HR}$ per $1 \mathrm{mg} / \mathrm{dl}$ increment $=1.68$, 95\% CI=1.03-2.58, $\mathrm{P}=0.039)$. Similar results were obtained using the multivariate Cox proportional hazards model. The patients were allocated into two subgroups according to the median value of SAA or CRP. The survival curves were estimated by the Kaplan-Meier method and differences in survival rates were compared using the log-rank test. The patients with higher SAA $(\mathrm{P}=0.0043)$ or CRP levels $(\mathrm{P}=0.0019)$ in the pre-vaccination samples exhibited worse prognosis (Fig. 2). 
Table III. Univariate and multivariate analyses with pre-vaccination clinical findings and laboratory data.

\begin{tabular}{|c|c|c|c|c|}
\hline \multirow[b]{2}{*}{ Factor } & \multicolumn{2}{|c|}{ Univariate analysis } & \multicolumn{2}{|c|}{ Multivariate analysis } \\
\hline & Hazard ratio $(95 \% \mathrm{Cl})$ & P-value & Hazad ratio $(95 \% \mathrm{Cl})$ & P-value ${ }^{a}$ \\
\hline Age (years) & $1.58(0.40-6.44)$ & 0.52 & & \\
\hline Gender (female<male) & $0.98(0.52-1.95)$ & 0.96 & & \\
\hline Clinical stage (IVa<recurrent $<\mathrm{IVb})$ & $1.18(0.78-1.80)$ & 0.43 & & \\
\hline Duration of previous chemotherapy (months) & $0.98(0.94-1.02)$ & 0.27 & & \\
\hline Regimen no. of previous chemotherapy & $0.93(0.59-1.44)$ & 0.75 & & \\
\hline Lymphocyte count $\left(\times 10^{2} / \mathrm{mm}^{3}\right)$ & $1.00(1.00-1.00)$ & 0.39 & & \\
\hline Hemoglobin $(\mathrm{g} / \mathrm{dl})$ & $0.93(0.75-1.16)$ & 0.53 & & \\
\hline Albumin $(\mathrm{g} / \mathrm{dl})$ & $0.58(0.32-1.10)$ & 0.09 & & \\
\hline Creatinine (mg/dl) & $1.88(0.51-5.23)$ & 0.31 & & \\
\hline $\mathrm{SAA}(\mathrm{mg} / \mathrm{dl})$ & $1.09(1.03-1.15)$ & $0.004^{\mathrm{b}}$ & $1.08(0.99-1.18)$ & 0.09 \\
\hline CRP (mg/dl) & $1.68(1.03-2.58)$ & $0.039^{\mathrm{b}}$ & $0.95(0.41-2.06)$ & 0.91 \\
\hline
\end{tabular}

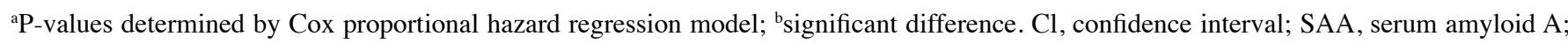
CRP, C-reactive protein.

In addition, concerning post-vaccination samples, the patients with boosted $\mathrm{IgG}$ responses $(\mathrm{n}=19)$ [in response to the vaccinated $(n=14)$ or unvaccinated peptides selected for the 2 nd cycle of PPV $(n=5)]$ exhibited better prognosis compared to those with no IgG boosting $(\mathrm{n}=17)(\mathrm{P}=0.0485)$ (data not shown).

\section{Discussion}

The MST of 41 chemotherapy-resistant advanced pancreatic cancer patients under PPV was 7.9 months with a 1-year survival rate of $26.8 \%$. Among them, the MST in patients treated with PPV combined with $(n=33)$ or without $(n=8)$ chemotherapies was 9.6 or 3.1 months, respectively $(\mathrm{P}=0.0013)$. OS of the patients treated with PPV not combined with chemotherapies was significantly short, suggesting that PPV alone did not provide survival benefits to advanced pancreatic cancer patients. This failure was expected based on the results from our previous study (13). These results suggest that PPV has the potential to improve OS in chemotherapy-resistant advanced pancreatic cancer patients when administered in combination with chemotherapeutic agents.

With regard to post-vaccination biomarkers, several factors, including CTL responses, Th1 responses, delayed-type hypersensitivity (DTH) and autoimmunity, have been reported to be associated with clinical responses in some clinical trials $(14,15)$. We have also shown that an increase in peptide-specific IgG and/or CTL responses after PPV is significantly associated with longer OS $(11,12)$. In contrast to such post-vaccination biomarkers, there are currently no validated pre-vaccination prognostic biomarkers widely used. Therefore, this issue was addressed in the present study. As a result, plasma SAA and CRP levels were inversely correlated with OS. These results were expected based on our previous study on PPV (10). These biomarkers are suggested to be important not only in cancer vaccines, but also in other treatment modalities for advanced pancreatic cancers.
Collectively, due to the safety profile and the potential clinical efficacy of PPV, further clinical trials to determine a protocol suitable for PPV-based therapy in chemotherapy-resistant advanced pancreatic cancer patients are warranted.

\section{Acknowledgements}

This study was supported in part by grants from the Regional Innovation Cluster Program, a research program of the Project for Development of Innovative Research on Cancer Therapeutics (P-Direct), the Ministry of Education, Culture, Sports, Science and Technology of Japan, and the Sendai Kousei Hospital, Japan.

\section{References}

1. Kindler HL, Ioka T, Richel DJ, et al: Axitinib plus gemcitabine versus placebo plus gemcitabine in patients with advanced pancreatic adenocarcinoma: a double-blind randomised phase 3 study. Lancet Oncol 12: 256-262, 2011.

2. Okada T, Kamada T, Tsuji H, et al: Carbon ion radiotherapy: clinical experiences at National Institute of Radiological Science (NIRS). J Radiat Res 51: 355-364, 2010.

3. Nakamura K, Yamaguchi T, Ishihara T, Sudo K, Kato H and Saisho H: Phase II trial of oral S-1 combined with gemcitabine in metastatic pancreatic cancer. Br J Cancer 94: 1575-1579, 2006.

4. Conroy T, Desseigne F, Ychou M, et al; Groupe Tumeurs Digestives of Unicancer and PRODIGE Intergroup: FOLFIRINOX versus gemcitabine for metastatic pancreatic cancer. N Engl J Med 364: 1817-1825, 2011.

5. Moore MJ, Goldstein D, Hamm J, et al: Erlotinib plus gemcitabine compared with gemcitabine alone in patients with advanced pancreatic cancer: a phase III trial of the National Cancer Institute of Canada Clinical Trials Group. J Clin Oncol 25: 1960-1966, 2007.

6. Pelzer U, Schwaner I, Stieler J, et al: Best supportive care (BSC) versus oxaliplatin, folinic acid and 5-fluorouracil (OFF) plus BSC in patients for second-line advanced pancreatic cancer: a phase III study from the German CONKO-study group. Eur J Cancer 47: 1676-1681, 2011.

7. Yanagimoto $\mathrm{H}$, Mine $\mathrm{T}$, Yamamoto $\mathrm{K}$, et al: Immunological evaluation of personalized peptide vaccination with gemcitabine for pancreatic cancer. Cancer Sci 98: 605-611, 2007. 
8. Yanagimoto H, Shiomi H, Satoi S, et al: A phase II study of personalized peptide vaccination combined with gemcitabine for non-resectable pancreatic cancer patients. Oncol Rep 24: 795-801, 2010.

9. Terasaki M, Shibui S, Narita Y, et al: Phase I trial of a personalized peptide vaccine for patients positive for human leukocyte antigen-A24 with recurrent or progressive glioblastoma multiforme. J Clin Oncol 29: 337-344, 2011.

10. Terazaki Y, Yoshiyama K, Matsueda S, et al: Immunological evaluation of personalized peptide vaccination in refractory small cell lung cancer. Cancer Sci 103: 638-644, 2012.

11. Noguchi M, Mine T, Komatsu N, et al: Assessment of immunological biomarkers in patients with advanced cancer treated by personalized peptide vaccination. Cancer Biol Ther 10: 1266-1279, 2011.
12. Mine T, Sato Y, Noguchi M, et al: Humoral responses to peptides correlate with overall survival in advanced cancer patients vaccinated with peptides based on pre-existing, peptide-specific cellular responses. Clin Cancer Res 10: 929-937, 2004.

13. Yamamoto $\mathrm{K}$, Mine $\mathrm{T}$, Katagiri $\mathrm{K}$, et al: Immunological evaluation of personalized peptide vaccination for patients with pancreatic cancer. Oncol Rep 13: 874-883, 2005.

14. Lopez MN, Pereda C, Segal G, et al: Prolonged survival of dendritic cell-vaccinated melanoma patients correlates with tumor-specific delayed type IV hypersensitivity response and reduction of tumor growth factor beta-expressing $\mathrm{T}$ cells. J Clin Oncol 27: 945-952, 2009.

15. Firpo MA, Gay DZ, Granger SR, et al: Improved diagnosis of pancreatic adenocarcinoma using haptoglobin and serum amyloid A in a panel screen. World J Surg 33: 716-722, 2009. 